\section{Research Article}

(c) 2020 Zhao et.al.. This is an open access article licensed under the Creative Commons Attribution-NonCommercial 4.o International License (https://creativecommons.org/licenses/by-nc/4.o/)

\title{
Hybridization of the Cultural Identity in Disney's Mulan
}

\author{
Zhao Meijuan $^{1,2}$ \\ Ang Lay Hoon ${ }^{1 *}$ \\ Florence Toh Haw Ching ${ }^{1}$ \\ ${ }^{1}$ Faculty of Modern Languages and Communication, \\ Universiti Putra Malaysia, Malaysia \\ ${ }^{2}$ Foreign Languages Department, \\ Baise University, China \\ ${ }^{*}$ Corresponding Author
}

DOI: https://doi.org/10.36941/ajis-2020-0o83

Abstract

Hybridization has become a fluid notion due to its association with ideas and themes that were once mutual contradicting but have now become mutual celebrated. However, such changes are inevitable as the trend of globalization continuously generates new transnational cultural elements. This study will examine the hybrid cultural identity in Disney's animated film Mulan (1998) which was adapted from The Ballad of Mulan, a folktale that originated from China. Specifically, it focuses on the cultural identity of Disney's Mulan and explores how it is reconstructed as a transnational culture which flowed from China to America. This phenomenon, to some extent, implies the West's increasing acceptance of cultural productions from Asian countries. The paper employs Daphne A. Jameson's analytic model of cultural identity consisting of vocation, class, geography, philosophy, language, and biological components which seek to examine the emergence of mixed and relational and hybrid cultural identities. Through this study, the paper aims to discuss how the process of hybridization brings the character's cultural identity in the original folklore to an international audience and how this facilitates cultural exchange and growth. The findings show that hybridization in cultural identity presents a tension between cultural Americanization and orientalization as well as modernity and tradition, which ultimately leads to a transferable cultural identity. The study is significant in elevating the status of Chinese folktales and highlighting cultural hybridity as a mediating factor in the growing trend of cultural globalization.

Keywords: Hybridization; Cultural identity; Mulan; Chinese folktale; Disney

\section{Introduction}

The late $20^{\text {th }}$ century has witnessed crucial changes in the interaction between national cultures as they confront the reality of global integration. Globalization has become a key influencer in various socio-political and cultural dimensions. As a result, an intriguing phenomenon has emerged in the form of a new and hybrid cultural space fused into the original boundaries of national culture and identity. This has led to increasing demands for intercultural and cross-cultural adaptations of folktales and legends which are re-packaged to suit the needs and tastes of a transnational audience.

The notion of hybridization is considered an effective tool that can enhance cultural vitality and 
facilitate the development of literary works. Within the scope of cultural studies, hybridization refers to the fusion of diverse cultural elements or forms which ultimately generates new cultural forms yet are inter-connected with one another (Wang, 2017). From this standpoint, cross-cultural fusion is reinforced in the process of hybridization. In meeting the demands of a global audience separated by cultural barriers and geographical borders, there appears to be a recent surge of appetite for cultural productions, specifically those originating from China. One example is Disney's adaptation of the Chinese folktale The Ballad of Mulan into the 1998 animated film, Mulan, as well as the latest 2020 live-action movie of the same title. This has sparked a new wave of interest across the continents.

A review of Disney's modus operandi in adapting cross-cultural folktales reveals that early prototypes of the origin culture are Americanized when transferred to screen (Malfroid, 2009; Bălinişteanu, 2014). An instance can be seen in the roles played by the dwarf characters in the tale of Snow White by the Brothers Grimm. While the original story casts them in minor roles, Disney has transformed these dwarfs into hardworking miners with commendable work ethics, thus reflecting the ideals of the American Dream. As for The Ballad of Mulan, the original folktale tells of Hua Mulan who was forced to impersonate herself as a male soldier to replace her elderly father's commissioning to serve in the military. However, Disney has transformed the Chinese heroine into an American tomboy who goes to war to prove her worth (Chen, 2018). Again, this fits the coveted image of the independent American girl, a celebrated icon during the heyday of the third wave feminist movement. Setiawati (2016) further observes that Disney's Mulan is a mirror for the American feminist idea which encourages the view that a woman is capable of achieving what a man can achieve.

The paper thus argues that Disney's reconstruction of the character Mulan from her Oriental origin into an Americanized image shows how Chinese folktales are re-narrated for global consumption. As new cultural forms or hybrids continue to be produced through the processes of cross-cultural, intercultural and transcultural convergence, the loss of the origin culture is inevitable. As demonstrated by Disney's adaptation of Mulan, the Chinese value of filial piety which governs the original story is lost in the latter. Despite that, Disney remains in favour of its hybrid characterization of Mulan. The excuse is that such an image heightens the dramatic conflict as these new cultural elements are believed to appear more desirable for the global market. In view of that, this study attempts to explore the implications of such hybridization in the debate on the character's cultural identity. Specifically, the discussion centers on Disney's reconstruction of Mulan's cultural identity in response to the transnational cultural flow from traditional China to modern America.

\section{Cultural Identity: An Abstract Complex}

Cultural identity is often reflected through an individual's values, behaviors, personality and patterns of interpersonal communication. It also encompasses other forms of social identification with shared characteristics such as ethnic, racial, and geographical origins (Wren, 2002; Unger, 2011). According to Hall (1990), these shared cultural codes provide us with a stable, unchanging, and continuous frame of reference and meaning. The positioning of an individual within a cultural community can therefore be determined via the person's physical appearance, behavior, ancestral origin and language, among others. In light of this, it is of little surprise to find an individual occupying several identities at different levels. This occurs when the individual identifies with numerous overlapping and non-overlapping cultural and subcultural groups (Raman, 2006; Spears, 2011).

The difficulty in defining and measuring the authenticity of one's cultural identity is widely acknowledged on account of the cultural diversities and individual differences exhibited (Matsumoto, 2003). The delineation of cultural identity therefore remains abstract and complex due to its fluid, dynamic and developmental nature which cuts across temporal and societal contexts (Weinreich, 2009). In its simplest sense, the formation of one's cultural identity is dependant upon the individual's sense of identification and belongingness within a predetermined cultural community. This sense of identity is further solidified through the strengthening of self-concept and positive 
views of the cultural groups (Harter, 1999). Notwithstanding that, the advent of technology has blurred the boundaries of such a definition. As media and communication allow for rapid crossborder exchanges, the creation of hybrid spaces becomes accelerated. Although cultural identities shaped by a mixture of familiar elements across different cultures are easily disseminated across national borders (Jenkins et al., 2013), pertinent questions such as "Who am I?", "Where do I come from?", "What belongs to us?" invite debate and clarification.

Despite the breadth of research surrounding the notion of cultural identity, there remains a scarcity in research on cultural identity integration (Ward et al., 2018). There is thus limited evidence to discuss the formation of new and diverse cultural identities and ascertain which of these cultural identities are a direct product of hybridity. Given these gaps within the realm of cultural studies, the study employs Daphne A. Jameson's cultural identity model outlining the categories of vocation, class, geography, philosophy, language, and biology to sharpen the formation of cultural identity. Table 1 further exhibits Jameson's model of categorization with their sub-categories. By discussing the exact elements which contribute to shape one's cultural identity, this study uses the example of Disney's Americanized adaptation of the Chinese folktale character Mulan to demonstrate how hybrid transnational cultural identities are created.

Table 1. Components of Cultural Identity（Jameson, 2007, p. 211）

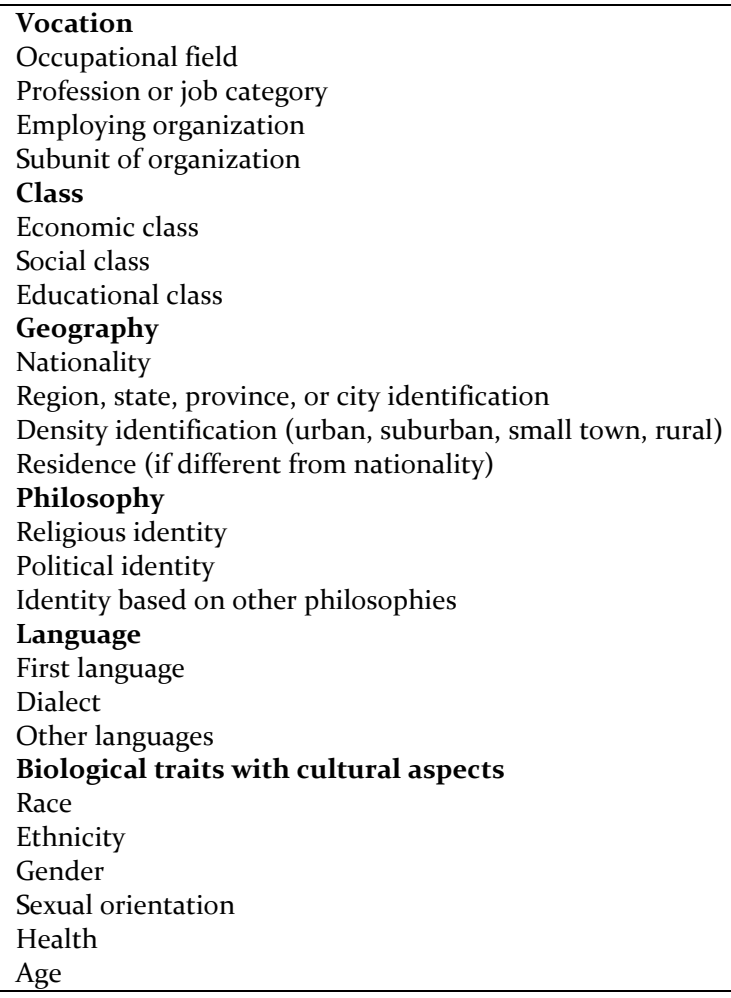

\section{Material}

The marketing strategy surrounding Disney's Mulan has cemented the reputation and status of its protagonist as an internationally influential icon (Jing, 2011). Owing to that, the study focuses on the film because it exhibits obvious traits of hybridity between Chinese and American cultures. 
Historically, Mulan is a household heroine who epitomises filial piety towards her parents and loyalty towards her nation. The Ballad of Mulan, which was believed to be composed between the 4 th and 6th century in China is widely acknowledged as the earliest version of the legend of the heroine. The text was compiled during the 11th century by scholar Guo Maoqian in an anthology of lyrics, songs and poems called Yuefu Shiji, meaning a collection of poems from Yuefu. Yuefu is acknowledged as a professional institution committed to composing music, collecting lyrics, and training musical talents during the Han Dynasty. The ballad is comprised of only 392 words including punctuation marks. In it, a female warrior named Hua Mulan took her elderly father's place to join the army during the Northern Dynasty (386-581AD). This occurred when the Khan rulers of the Northern Dynasty decreed that a male representative from each family must join the army to defend the region against enemy invaders. Her father, although aged, had also been enlisted. Since Mulan had no elder brother in the family and she did not want her aged father to suffer the hardships of serving in the army and facing the war, she disguised herself as a man and reported into the army in place of her father. Having fought against the invaders and returned home triumphant, Mulan's male comrades were then shocked to discover that she was in fact, a woman. This ending for the heroine in the ballad is starkly different from the one Disney adapted. In the original poem, Mulan guarded the truth about her gender throughout the war whereas the film version showed her true identity being revealed during the war. This led to her dismissal from the army.

In most parts, Disney's animated film Mulan (1998) had retained the basic premise of the folktale. In Disney's Mulan, Fa Mulan had decided to take her ailing father's place to fight in the war. She also disguised herself as a young man to serve in the military. After the troop's triumph, Mulan turned down the royal rewards bestowed upon her and returned home to resume her life as a woman. The differences between the film and the original text are some added elements such as a small dragon called Mushu, Mulan's interview with the matchmaker, the revelation of her identity as a female and the Emperor's praise for her. In Disney's version of the folktale, the heroine was vivacious, headstrong and curious. As these characteristics do not meet the desirable quality of femininity and gentility within the Chinese culture, she failed to fulfill the matchmaker's requirement and therefore did not qualify to be recommended as a perfect bride. This incident dishonoured her family and brought her father's disappointment. Mulan herself began to question her sense of worth. It is during this juncture that the conscription notice arrived with a decree that each family should send a male member to join the army. Due to her father's diminishing health and hoping to redeem her family's honour, Mulan decided to take her father's place in the military. In this sense, Disney's Mulan highlights the themes of pursuit and affirmation of the self.

Despite its international repute, Disney's Mulan was not well-received in mainland China. Dong (2011) notes that the film has re-stylized Mulan as an American, thus distorting her authentic Chinese image. In addition, the Turkish Nationalist Movement Party has launched a protest against the film since "this animated film distorts and blackens the history of the Turks by showing the Huns as bad and the Chinese as peace-lovers" ("Turkey Nationalists Protest 'Mulan'," 1999). Notwithstanding that, the film which was released in 1998 grossed \$304.3 million ("Mulan”, 1998). The character Mulan went on to join the ranks of Disney princesses alongside Cinderella, Snow White and Belle from Beauty and the Beast fairytale. Following that, Disney decided to release a sequel titled Mulan II (2005) and a liveaction film titled Mulan (2020). The global reception of the Mulan installments shows the imprint that a Chinese narrative has made on popular American culture.

\section{Methods}

This study utilizes a qualitative reading of Mulan's cultural identity through content analysis and comparative approach. Broadly speaking, content analysis is defined as "any technique for making inferences by objectively and systematically identifying specified characteristics of messages" (Holsti, 1969, p. 14). Comparative approach refers to a scientific method in which "two or more cases are explicitly contrasted to each other [sic] regards to a specific phenomenon or along a certain 
dimension, in order to explore parallels and differences among the cases" (Azarian, 2011, p. 113). This paper examines the hybridization of cultural identities in Disney's Mulan based on Jameson's cultural identity model. The character's cultural identity is first examined through the six categories set out in Jameson's cultural identity model. The film is then compared to The Ballad of Mulan to highlight how cultural hybridization has taken place between the original folktale and its contemporary adaptation.

\section{Findings and Discussion}

The reading of Disney's Mulan is enlightened through the components set out in Jameson's cultural identity model. These components explore how cultural identities are hybridized by means of vocation, class, geography, philosophy, language and biological traits coupled with cultural aspects. The following discussion details the analysis of the character according to the respective components.

\subsection{Vocation}

According to Narloch (2004), vocation can be synonymous with a person's occupation and can refer to someone being a teacher, driver, doctor, or nurse. It can also denote a person's position in relation to their immediate others, such as being a mother, father, daughter or son. For Jameson (2007), however, vocation-related groups often share distinctive cultures, attitudes and traditions in their fields. In the selected film, for instance, Mulan was a soldier. Her role thereby involves obeying her superior's orders, serving the country and bringing honour to her family and country.

Like all other young women in ancient and imperial China, Mulan was restricted from engaging in social activities. This means that she was not free to roam or travel around nor engage in entertainments in the form of games. Instead, she was required to follow the teachings of Confucius' Three Obedience and Four Virtues philosophies. The Three Obedience philosophy denotes that a woman should prioritize and obey her father before marriage, her husband in marriage and her son(s) in widowhood. The Four Virtues, on the other hand, refer to how a woman should observe feminine virtues, feminine words, feminine appearances, and feminine needle work. According to these teachings, therefore, Mulan's first vocation is her position as a daughter in the Fa family. This leads to her next mission which is to become the perfect bride who can please her husband and mother-in-law. In order to achieve these, she must be quiet and demure, graceful and polite, refined and poised. Any unfitting behaviour would be dishonourable to her family and clan. Mulan's participation in the military activates her second vocation. Being a soldier, albeit in disguise, necessitates her mission to protect her country. As military training becomes her daily routine, Mulan grows in courage, wisdom and potential. In this sense, the original Chinese text, The Ballad of Mulan, as well as Disney's animated film both utilize Mulan's vocation to present the identity, lifestyle and mission of young daughters and soldiers in ancient China.

\subsection{Class}

The second component of the cultural identity proposed by Jameson is class. While Howland (2001) considers this classification as of a group of people or things in which members share some measure of resemblance, Jameson (2007, p. 212) believes that "economic, social, and educational class often define groups of people who share common values, behavior, and attitudes". From this definition, Mulan's cultural identity is dependent upon her family's social class.

During the era of the Northern Dynasty in China, soldiers born into military families enjoyed direct promotion onto elevated social rankings and received privileged welfare during their service in the army. The family of a soldier who was killed in action would also be compensated with preferential treatment and enjoy a highly favoured status within the society. In The Ballad of Mulan, the class identity of Mulan's family can be ascertained through the following verse: 
昨夜见军帖 Last night I saw the draft posters,

可汗大点兵 The Khan is calling many troops,

军书十二卷 The army list is in twelve scrolls,

卷卷有爷名 On every scroll there's Father's name.

阿爷无大儿 Father has no grown-up son,

木兰无长兄 Mulan has no elder brother.

愿为市鞍马 I want to buy a saddle and horse,

从此替爷征 And serve in the army in Father's place.

东市买骏马 In the East Market she buys a spirited horse,

西市买鞍䩲In the West Market she buys a saddle,

南市买䅉头 In the South Market she buys a bridle,

北市买长鞭 In the North Market she buys a long whip. (Frankel, 1976)

The verse shows how Mulan's father remained a notable figure within the military despite his advanced age. As such, his service was urgently needed while the country was under threat. Mulan's concern towards her father's capability to serve in the military propelled her to take his place. In her preparation to join the army, the protagonist purchased a spirited horse, a saddle, a bridle and a long whip. Within the context of a nation at war with political and economical chaos, social instability and currency inflation are inevitable. Despite the socio-economical turmoil surrounding this critical period, Mulan's purchase of the military items shows the extent of her family's wealth.

This is further corroborated by Disney's version of the folktale where Mulan's family residence is shown with a big courtyard and ancestral shrine, thus signifying their economic status. The admiration with which Li Shang, Mulan's military superior, expressed towards her father is also evidence of their social standing. Not only that, a closer examination of Mulan's father's hairstyle shows a resemblance to the Chonmage, a typical Japanese Samurai hairstyle popularized during the Tokugawa era (1603 AD -1868 AD). The Chonmage hairstyle is spotted with the top of the head clean shaven while the remainder of the hair at the side and back pulled into a top knot. Such a style was originally utilized by the Samurai for ease of securing their helmet during a fight. As time passes, the hairstyle gradually evolved into a symbol of social identity and honour for the Samurai warrior (Vaporis, 2019). Howland (2001) notes that the Chonmage hairstyle is not only found in Japan but can also be seen in communities with shared cultures between the "nomadic peoples in Japan, Mongolia and Korea" (Park, 2008, p. 10). Just as the Samurai occupied a position within the ruling class and bureaucratic elite, the portrayal of Mulan's father exhibiting a similar hairstyle also implies his elevated class identity. In this aspect, Disney attempts to depict the protagonist's class identity to the global audience.

\section{$5 \cdot 3$ Geography}

According to Jameson (2007), geographical borders not only create cultural groups but can also affect the values, attitudes, and behaviors of large groups of people. Anderson et al. (2003) maintain that geographic regions further "express a defined cultural homogeneity" (p. 3) such as ethnicity, tradition and terminologies unique to the culture. Nevertheless, the interaction between cultures as well as the intersection of geographical borders allows for the production of hybrid identities which can be explored.

For example, Disney's Mulan begins with images of traditional Chinese calligraphy and painting, a red Chinese dragon, and the Great Wall of China, all of which bring the audience into an ancient, traditional and oriental setting. These images also provide clues to the story's geographical location. While the film is replete with details pointing to the protagonist's Chinese origin, it never clarified whether she was from the northern or southern parts of China. In contrast to that, an understanding of the history of Chinese literature points to Mulan originating from the northern regions of China (Dong, 2011). The verse “旦辞爷娘去, 暮宿黄河边” [At dawn, she takes leave of Father and Mother, in 
the evening camps on the Yellow River's bank] in The Ballad of Mulan implies that Mulan probably lived near the Yellow River, which flows through the northern provinces including Henan, Shanxi and Shandong, to name a few.

While it is unclear whether Disney's production team was deliberate in modifying the setting of the story, the film contains cultural elements commonly associated with Southern China. For example, Mulan's family name has been changed from "Hua" to "Fa". According to Shaffer (2O10), "Fa" is the Cantonese pronunciation of Mulan's family name while "Hua" is the correct Chinese Mandarin pronunciation which means "flower". Cantonese is a Chinese dialect used in the southern parts of China predominantly in Guangdong and Hongkong. As such, the use of "Fa" as the family name in the film implies that Mulan hails from a Southern Cantonese-speaking region. Another indicator of this is the presence of a magnolia tree in the garden of Mulan's family residence. This is apparent in the scene after Mulan fails to satisfy the matchmaker's requirement. As Mulan's father sits with her under the magnolia tree, he pointed to the flowers and said, "This one's late, but it can be the most beautiful flower. Someday Mulan can bloom like the flower". Such is a father's love in comforting his grieving daughter. According to Yan et al. (2018), the magnolia is a type of plant that blooms in early spring and is commonly found in the southern part of China. From these examples, it appears that Disney is more inclined to place Mulan's birthplace in the southern part of China.

Other exotic objects also permeate Disney's adaptation of Mulan. In a scene showing a destroyed village in the aftermath of the war, a child's doll bearing Japanese characteristics was shown. According to Shaffer (2010), the doll is a tribute to Hayao Miyazaki's Nausicaä of the Valley of the Wind (1988) where a warrior finds the same doll in an abandoned village. This element positions the setting of the film in Japan rather than China. This mixed setting of a Chinses tale containing Japanese elements reveals a cultural hybridity shared among Asian countries which share geographical borders as neighbours.

\subsection{Philosophy}

Based on Jameson's (2007) model of cultural identity, the philosophy held by a cultural group can cut across nationalities and ethnicities. This includes religious beliefs and shared communal worldviews. With regards to the Chinese culture, the concept of filial piety is succinctly illustrated by the Chinese character “孝" [filial piety]. The structure of the word is an ideogram made up of two characters: the top part of the character being “老” [old] while the bottom half consists of “子” [son]. In its top-down combination, the "old" character being on top of the "son" character signifies the old supported by the young, or that the young is burdened and oppressed by the old. The notion of filial piety thus carries the continuation of the family line, that is the father produces the son (Ikel, 2004). The understanding of filial piety is further summed up in the statement “身体发肤, 受之父母, 不敢毁伤, 孝 之始也” [The body, hair and skin, all have been received from the parents, and so one doesn't dare damage them-that is the beginning of filial piety].

Observing filial piety - a virtue for respecting one's parents, elders and ancestors - is central to Confucian teachings which have greatly influenced the development of education and parental authority in China. This concept guards the customary relations in China where the citizens are expected to show their loyalty to the Emperor while the younger generation is expected to show their obedience to their elders. Thus in The Ballad of Mulan, Hua Mulan was driven by filial piety to take her father's place in service to the military.

An analysis of Disney's Mulan reveals a version of obedience that contrasts the traditional Confucian teaching of filial piety. In the film, Mulan is depicted as a daughter who was dissatisfied at being confined by the rigidity of her cultural norms. This Americanized version of the protagonist strives to find her real self and pursue the rights of expression. In the scene where her father was called to serve the army, Mulan boldly begged the Prime Minister to exempt her aged and ailing father. Following conventional Confucian principles, a young female is not allowed to correct a senior 
male's decision. Mulan's action in the film has thus brought disgrace to her father. Furthermore, during the family's dinner scene, the heroine tried again to persuade her father:

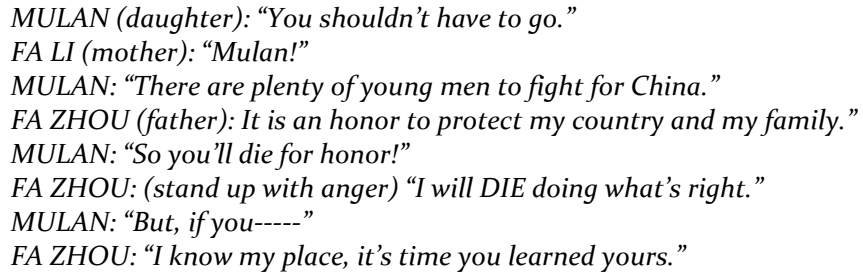

Caught in the dilemma between vocalizing her individuality and following the societal expectations of a young Chinese woman, Mulan chose the former. By choosing to redeem her family's honour and proving her capability instead of observing filial piety, the film shows the character's "development from a Chinese folk heroine to an extraordinary Chinese American woman warrior" (Dong, 2011, p. 94).

\subsection{Language}

Language constitutes the most obvious and apparent aspect of cultural identity (Bhugra et al., 1999). Similarly for Jameson (2007), different cultural groups possess specific language habits and preferences which result in "dialects, specialized vocabularies and styles of expression that serve to define membership in certain cultural groups" (p. 214). The Ballad of Mulan was written in ancient Chinese language which gave hints to the lifestyle of an ancient dynasty whose written and verbal interactions differ from modern Chinese communities.

Although Disney's Mulan has also been dubbed into other international languages, the use of Chinese scripts in the film's backdrop remains consistent throughout the movie. For example, the writings on the temple stones are the names of the Disney animators written in ancient Chinese characters (Shaffer, 2010). A point worth considering is how Disney refers to Mulan's motherland as China without mentioning the exact dynasty. Informed audience may find this reference ambiguous as it does not specify the historical context of the story. Scholars observe that Chinese native speakers usually refer to the setting in The Ballad of Mulan as the Northern Dynasty. This example shows how language can represent the complexity of Mulan's hybrid cultural identity.

\subsection{Biological traits with cultural aspects}

The final component of cultural identity outlined by Jameson is the individual's biological traits combined with cultural aspects. These include a person's race, ethnicity, gender, sexual orientation, health and age. According to Jameson (2007), a person's biological traits carry social influences. Through social interactions, the community develops a coherent and shared view about life's concerns, acceptable attitudes and appropriate decorum.

In Disney's animated film Mulan featuring the family tree, it is observed that one of Mulan's ancestors exhibited American features. This occurred when Mushu woke her ancestors and was greeted by a pair of elderly couple who was worried that Mulan would bring trouble to the whole family. Shaffer (2010) points out that these characters resemble the elderly couple living on the farm in Grant Wood's painting entitled American Gothic. Disney's adaptation of the folktale is therefore considered a hybrid between Chinese and American cultures which, to some extent, influences the heroine's cultural identity.

Lastly, it is worth discussing the portrayal of Mulan's gender and sexuality. The social status of her family notwithstanding, Mulan herself is positioned in a lower status due to her gender. It should be clarified that in the traditional Chinese culture, both the female and male genders occupy an equal 
position within the symbolic and mutually harmonious system of Yin (earth) and Yang (sky) respectively. This is outlined in The Book of Changes (Zhou Yi, 周易) which also specifies the roles and duties of both sexes:

女正位平内, the wife has her correct place in the inner (trigram, Ba Gua),

男正位乎外, and the man his correct place in the outer.

男女正, That man and woman occupy their correct places

天地之大义。is the great righteousness shown (in the relation and positions of) heaven and earth.

The distinguishing roles of men governing affairs outside the house while women were put in charge of household matters became misconstrued during the feudal governance of the Han Dynasty $(202 \mathrm{BC}-220 \mathrm{AD})$. Consequently, the men's contributions to the society were highly regarded as the significance of the women's contributions diminished in value, rendering them socially inferior to their male counterparts. This is exemplified in Disney's animated version of Mulan where she was cast as being dishonourable for speaking in front of a group of men without prior permission.

Not only that, in The Ballad of Mulan, the heroine's gender was not discovered by the military until the end of the story. In other words, Mulan had disguised herself as a male soldier from the beginning until the end of the war. Her comrades thus regarded her as a male hero who was merely fulfilling her designated role. The call for gender equality was only delivered at the end of the poem with the verse "How can they tell if I am a he or she?"

\section{出门看火伴 She goes out the door and sees her comrades. \\ 火伴皆惊惶 Her comrades are all amazed and perplexed. \\ 同行十二年 Traveling together for twelve years \\ 不知木兰是女郎 They didn't know Mulan was a girl. \\ 雄免脚扑朔 'The he-hare's feet go hop and skip, \\ 雌免眼迷离 The she-hare's eyes are muddled and fuddled. \\ 双免傍地走 Two hares running side by side close to the ground, \\ 安能辨我是雄雌 How can they tell if I am he or she?' (Frankel, 1976)}

In Disney's Mulan, however, the heroine's gender was discovered while she was in service in the army. As a direct consequence of the discovery, she was relegated to the image of an imposter who had lied to the army and was to be put to death. She also lost her credibility and the trust of her comrades who no longer believed in what she said. This proved detrimental to the army troops when she tried to warn them of the enemy's presence and threat. The climax of the film shows the Khan military at the brink of defeat before Mulan rode in to save her comrades, thus winning the war for her nation. The story ends with Mulan being granted royal pardon for her service to the country. Her highest honour was having the Emperor bowing to her in appreciation, a gesture followed by the rest of the citizens of China. This scene is the culmination of Mulan's achievement as it shows the heroine finally gaining her self-identity while upholding gender equality. The cultural hybridization found in Disney's Mulan is evident as the heroine plays the multiple roles of a young female in conservative the Chinese society, a male soldier who transforms into a female soldier, and finally a rebel trying to break free from the oppressive treatment imposed upon a woman's role in the society. These multiple identities thus show how Disney creates a narrative centered around female empowerment.

The ending of the story, according to Disney's animated, film also differs from the original Chinese folktale. Disney's Mulan closes with the heroine receiving a warm welcome from the army general's son, a subtle reference to the potential of a happy marriage for the protagonist. This lighthearted and comedic ending exemplifies a kind of "Disneyfication" which is a "process when a complex fairy tale is separated from its grim elements and then romanticized and sweetened" (Christina \& Suprajitno, 2014). 


\section{Conclusion}

The discussion shows how the portrayal of Mulan's cultural identity within the film has greatly deviated from its original text. Through Jameson's proposed model of cultural identity, this study examines the components which make up the cultural identity of Disney's Mulan from her vocation, class, geography, philosophy, language and her biological traits in tandem with cultural influences. By reframing Mulan's cultural identity from the contemporary American context, Disney attempts to amplify Western cultures and values to cater to the expectations of a global audience hitherto satiated by the fanfare of Hollywood extravagance. In this sense, the tensions brought by the clash of American versus oriental cultures as well as the contrast between tradition and modernity are heightened since the film presents radical changes when compared against the original text. Disney, with its continuous attempts to instigate the hybridization of Eastern and Western cultural elements, produces an ambiguous and thereby problematic cultural identity leading to the loss of cultural particularity in the archetype of the Chinese heroine, Hua Mulan.

Concluding, it should be clarified that the purpose of this study is not to judge whether the hybrid cultural identity is good or bad. Rather, it focuses on how Jameson's model is useful to study the hybridization of cultural identities. While the emergence of the hybrid conditions the international audience to accept a cultural product of mixed identities, it could also lead to the discontinuity or extinction of the culture of origin. Ultimately, such occurrences are inevitable as the ongoing global trend continues to witness the mingling of multi-cultural elements, resulting in the birth of a new hybrid exhibiting characteristics distinctive from its cultures of origin. In sum, the study hopes to inspire further studies on the hybridization of Western and Eastern cultures - an example being Hollywood's current attempt at re-casting the Chinese mythical hero, Nezha, a project which is currently in production.

\section{Acknowledgement}

This work was supported by the 2019 National Social Science Foundation of China under Grant number 19CYYo12; 2018 Philosophical and Social Science Program of Guangxi Zhuang Autonomous Region under Grant number 18FYYoog; 2018 Philosophical and Social Science Program of Guangxi Zhuang Autonomous Region under Grant number 18BYYoo1.

\section{References}

Anderson, K., Domosh, M., Pile, S., \& Thrift, N. (2003). Handbook of Cultural Geography. Sage. https://doi.org/10.1192/bjp.111.479.1009-a

Azarian, R. (2011). Potentials and limitations of comparative method in social science. International Journal of Humanities and Social Science, 1(4), 113-125.

Bălinişteanu, C. (2014). The Disneyfication of Children's Literature. Interstudia (Revista Centrului Interdisciplinar de Studiu Al Formelor Discursive Contemporane Interstud), 15, 86-94. https://doi.org/10.1016/j.cplett.2006.09.084

Bhugra, D., Bhui, K., Mallett, R., Desai, M., Singh, J., \& Leff, J. (1999). Cultural identity and its measurement : a questionnaire for Asians. International Review of Psychiatry, 11, 244-249.

Chen, X. (2018). Representing cultures through language and image: a multimodal approach to translations of the Chinese classic Mulan. Perspectives: Studies in Translatology, 26(2), $214-231$. https://doi.org/10.1080/0907676X.2017.1365911

Christina \& Suprajitno, S. (2014). The Americanization of Confucian Filial Piety in Disney' s Mulan ( 1998 ). Journal of Language, Literature, and Teaching, 2(1), 29-35.

Dong, L. (2011). Mulan's legend and legacy in China and the United States. Temple University Press. https://doi.org/10.1192/bjp.111.479.1009-a

Feng, Xinming (2008). Xiao Jing- the Classic of Xiao with English Translation E Commentary. http://www.tsoidug.org/Xiao/Xiao_Jing_Comment.pdf

Frankel, H.H. (1976). The Flowering Plum and the Palace Lady: Interpretations of Chinese Poetry. Yale University Press. 
Hall, S. (1990). Cultural identity and Diaspora. In J. Rutherford, J. (Ed.), Identity, (pp. 222-237). Lawrence \&Wishart.

Harter, S. (1999). The construction of the self: A develop- mental perspective. Guilford.

Holsti, O.R. (1969). Content Analysis for the Social Sciences and Humanities. Reading. Mass: Addison-Wesley Pob. Co.

Howland, D. R. (2001). Samurai Status, Class, and Bureaucracy: A Historiographical Essay. The Journal of Asian Studies, 6o(2), 353-380. https://doi.org/10.2307/2659697

Jameson, D. A. (2007). Reconcetpualizing Cultural Identity and Its Role in Intercultural Business Communication. Journal of Business Communication, 44(3), 199-235. https://doi.org/10.1177/0021943607301346

Jenkins H, Ford, S. \&Green J. (2013). Spreadable Media : Creating Value and Meaning in a Networked Culture. New York University Press.

Jing, Y. (2011). Popular culture and public imaginary: Disney vs. Chinese stories of Mulan. Javnost, 18(1), 53-74. https://doi.org/10.1080/13183222.2011.11009051

Malfroid, Kirsten (2009). Gender, Class and Ethnicity in the Disney Princesses Series (Master's thesis, Gent University, Gent, Belgium). https://lib.ugent.be/fulltxt/RUGo1/oo1/414/434/RUGo1-001414434_2010_ooo1_AC.pdf

Matsumoto, D. (2003). The discrepancy between consensual-level culture and individual-level culture. Culture $\mathcal{E}$ Psychology, 9(1), 89-95.

Mulan. (1998). Box Office Mojo by IMDbPro. https://www.boxofficemojo.com/release/rl3664086529/weekend/

Narloch, R. (2004). College Students' Conceptions of Vocation and the Role of the Higher Education Mentoring Community. Journal of College and Character, 5(5). https://doi.org/10.2202/1940-1639.1384

Park, Y. (2008). A Living Cultural Area of the Northeast Asia Region in Maritime Perspective with Special Reference to Historical, Environmental and Security Problems. Annual Research Bulletin of Osaka Sangyo University, 1, 1-36.

Raman, S. (2006). Cultural identity and child health. Journal of Tropical Pediatrics, 52, 231-234.

Setiawati, B. (2016). Americanization of Non-American Stories in Disney Films. Register Journal, 1(1), 79-110. https://doi.org/10.18326/rgt.vii1.81-114

Shaffer, J.C. (2010). Discovering the Magic Kingdom: an Unofficial Disneyland Vacation Guide. Author House.

Spears, R. (2011) Group Identities: The Social Identity Perspective. In: Schwartz S., Luyckx K., Vignoles V. (eds) Handbook of Identity Theory and Research (pp.202-224). Springer. https://doi.org/10.1007/978-1-4419-79889-9

Turkey Nationalists Protest 'Mulan'. (1999, January 24). AP News.

https://apnews.com/eccebc96d9527c94508396ab9bdo344a

Unger, J. B. (2011). Cultural identity and public health. In S. J. Schwartz, K. Luyckx, \& V. L. Vignoles (Eds.), Handbook of identity theory and research (p. 811-825). Springer Science + Business Media.

Wang, J. (2017). Hybridization as Global Cultural Production Strategy: A Case Study in Disney Animation. Advances in Social Science, Education and Humanities Research, 171, 270-273. https://doi.org/10.2991/icassee17.2018.60

Ward, C., Ng Tseung-Wong, C., Szabo, A., Qumseya, T., \& Bhowon, U. (2018). Hybrid and Alternating Identity Styles as Strategies for Managing Multicultural Identities. Journal of Cross-Cultural Psychology, 49(9), 14021439. https://doi.org/10.1177/oo22022118782641

Weinreich, P. (2009). 'Enculturation', not 'acculturation': Conceptualising and assessing identity pro- cesses in migrant communities. International Journal of Intercultural Relations, 33, 124-139.

Vaporis, C. N. (2019). Samurai: An Encyclopedia of Japan's Cultured Warriors. ABC-CLIO.

Wren, T. (2002). Cultural Identity and Personal Identity: Philosophical Reflections on the Identity Discourse of Social Psychology. In A. W. Musschenga et al. (eds.), Personal and Moral Identity (pp. 231-258). Kluwer Academic Publishers.

Yan, S.X., Li, Y.H., \& Wei, F.Y. (2008). Geographical Distribution of Magnoliaceae Plants in China. Journal of Wuhan Botanical Research, 04, 379-384. 